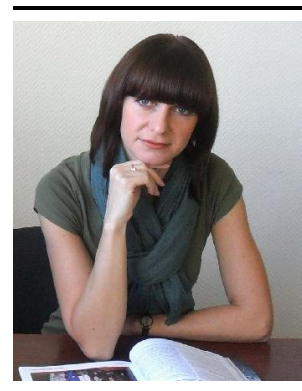

УДК 63-021.66.465 (100)

https://doi.org/10.47612/978-985-7149-55-1-2020-182-184

Ирина Почтовая, кандидат экономических наук, доцент, заведующий сектором качества

Институт системных исследований в АПК НАН Беларуси, г. Минск

\title{
Развитие инструментов управления качеством продукции АПК в мировой практике
}

Современные условия хозяйственной деятельности характеризуются все большей взаимозависимостью национальных экономик агропромышленного производства, интеграцией субъектов всех стадий производства и сбыта продукции, начиная с первичного сырья, в систему международного обмена, что делает их взаимообусловленными на международном уровне (в глобальном масштабе), в том числе и с точки зрения механизмов регулирования и обеспечения качества и безопасности продукции.

В настоящее время при регулировании качества продукции основополагающее значение принадлежит таким мерам, как правовое, нормативное обеспечение, контроль, стимулирование и др. Они направлены на формирование соответствующей среды производства в целях обеспечения конкурентоспособности продукции, эффективности использования имеющегося ресурсного, научно-технического, инновационного потенциала всех субъектов хозяйствования и отраслей в целом.

В отношении продовольственного (пищевого) права Европейского союза, которое начиная с 2002 г. подверглось существенным изменениям, следует отметить, что оно акцентирует внимание на следующих аспектах:

требования к производственным процессам;

требования и контроль импортируемой продукции; риск-ориентированный подход и обеспечение прослеживаемости продукции.

Особенностью европейского продовольственного права является установление базовых требований в определенной области, которые дополняются рядом более конкретных норм и правил. Так, до конца 2019 г. такого рода базовыми являлись четыре Регламента ЕС (178/ 2002, 853/2004, 854/2004, 882/2004). Два из них (178/2002, $882 / 2004)$ были отменены в связи с принятием Регламента 2017/625. Данный регламент предусматривает интеграцию требований к контролю пищевых продуктов и кормов, благополучию и защите животных, средств защиты растений, маркировке продуктов (в том числе органических и генно-модифицированных) и их концентрацию в одном документе, что помимо вышеназванных отмененных регламентов обусловило отмену и ряда директив [12].

В то же время следует подчеркнуть только основополагающую, а не исключительную роль названных регламентов, что выражается в их конкретизации и детализации рядом более специализированных документов, среди которых:

Регламент Совета (ЕС) № 1099/2009 от 24 сентября 2009 г. по защите животных во время убоя;
Директива Совета 2008/119/ЕС от 18 декабря 2008 г., устанавливающая минимальные требования к охране телят;

Директива Совета 2008/120/ЕС от 18 декабря 2008 г., устанавливающая минимальные требования к содержанию свиней;

Регламент (ЕС) № 1760/2000 Европейского парламента и Совета от 17 июля 2000 г., устанавливающий систему идентификации и регистрации крупного рогатого скота и касающийся маркировки говядины и продуктов из говядины, и отменяющий Регламент Совета (EC) № 820/97;

Регламент Европейского парламента и Совета (ЕС) 2019/6 от 11 декабря 2018 г. о ветеринарных лекарственных средствах;

Директива Европейского парламента и Совета 2003/ 99/ЕС от 17 ноября 2003 г. о мониторинге зоонозов и зоонозных агентов, внесении изменений в Решение Совета 90/424 / ЕЕС и отмене Директивы Совета 92/117/EEC;

Постановление Европейского парламента и Совета (ЕС) № 2160/2003 от 17 ноября 2003 г. о борьбе с сальмонеллой и другими пищевыми зоонозными агентами.

Необходимо также отметить, что продовольственное право ЕС посредством соответствующих регламентов и директив в большей степени устанавливает требования к безопасности продукции. В отношении качества следует отметить Делегированный регламент Комиссии (ЕС) 2017/1182 от 20 апреля 2017 г., дополняющий Регламент (ЕС) № 1308/2013 Европейского парламента и Совета в отношении шкалы ЕС по классификации туш крупного рогатого скота, свиней и овец и отчетности по рыночным ценам на отдельные категории туш и живых животных (ранее действовали: Регламент Комиссии (ЕС) № 1249/2008 от 10 декабря 2008 г., устанавливающий правила применения шкалы для классификации туш говядины, свинины и козлятины и соответствующие цены; Исполнительный регламент Комиссии (EU) № 148/2014 от 17 февраля 2014 г., вносящий изменения в Регламент (ЕС) № 1249/2008 от 10 декабря 2008 г. в отношении категорий и классов для рыночных цен на туши говядины и свинины).

В целях усиления прозрачности в области генномодифицированных организмов, кормовых добавок, материалов, контактирующих с пищевыми продуктами, пищевых добавок, ферментов и ароматизаторов, средств защиты растений и новых продуктов питания в 2018 г. Европейская комиссия инициировала пересмотр законодательства о пищевых продуктах. В результате принят новый Регламент (ЕС) 2019/1381 от 20 июня 2019 г. 
о прозрачности и устойчивости оценки рисков ЕС в пищевой цепи и внесении изменений в Регламенты (ЕC) № 178/2002, (EC) № 1829/2003, (EC) № 1831/2003, (EC) № 2065/2003, (EC) № 1935/2004, (EC) № 1331/2008, (EC) № 1107/2009, (ЕС) 2015/2283 и Директиву 2001/18/ЕС [11].

Данный документ направлен на достижение следующих целей:

- повышение прозрачности оценки рисков ЕС в пищевой цепи, в том числе с точки зрения расширения доступа потребителям к результатам исследования и информации по результатам оценки рисков;

- повышение надежности, объективности и независимости исследований, проводимых Европейским органом по безопасности пищевой продукции EFSA (European Food Safety Authority), посредством централизации и контроля всей информации о планируемых исследованиях;

- пересмотр структуры управления EFSA - участие государств-членов, общества и Европейского парламента в управлении путем должного представительства; - усиление научного сотрудничества и привлечение независимых экспертов к работе EFSA;

01 развитие системы комплексного информирования о рисках посредством принятия общего плана информирования о них, который обеспечит согласованную стратегию на протяжении всего процесса анализа рисков в сочетании с открытым диалогом между заинтересованными сторонами.

Новые положения основываются на результатах оценки эффективности (прежде всего с точки зрения комплексности) действующего общего законодательства в области регулирования пищевых продуктов [3].

Тенденции консолидации требований, а также обеспечения прозрачности движения продукции характерны и для законодательства ряда стран. В частности, в Канаде реформа законодательства в области пищевых продуктов привела к замене более десяти существовавших ранее нормативных актов посредством принятия в 2019 г. нового Закона «О безопасных продуктах питания» (Canada's Safe Food for Canadians Act - SFCA) и Положения о безопасных продуктах питания для канадцев (Safe Food for Canadians Regulations - SFCR).

В Законе акцент сделан на управление рисками, прослеживаемость, отзыв продукции с рынка в случае ее несоответствия. Кроме того, он направлен на регулирование рынка в целом, включая импортную продукцию, что позволяет обеспечить гарантию потребителям ее безопасности и доверие к канадской продукции на внешнем рынке [4, 6, 8].

В данном контексте следует отметить, что Канада и США (Canadian Food Inspection Agency and the US Food and Drug Administration) приняли решение о сближении и гармонизации законодательств в области безопасности пищевых продуктов [5].

В отношении контроля Европейское право предусматривает правила, принципы его организации и функционирования соответствующих систем применительно ко всем субъектам рынка, официальным (компетентным) органам, референтным лабораториям и др.
В то же время единые механизмы их реализации во всех странах-членах не предусматриваются.

В свою очередь, системы быстрого реагирования, прослеживаемости продукции следует отнести к элементам регулирования, которым в последние годы придается четко выраженное экономико-социальное значение, что подчеркивается при обосновании их актуальности европейскими органами управления в обозначенной области деятельности. В числе таких систем следует назвать Глобальную систему (программу) в области надзора за продовольствием GEMS/ FOOD (Global Environment Monitoring System/Food), Систему быстрого оповещения для пищевых продуктов и кормов RASFF (Rapid Alert System for Food and Feed) и др.

Обеспечение прослеживаемости, наряду с европейским, заложено и в национальных законодательствах стран и реализуется, как правило, государственными органами, выполняющими функции контроля безопасности продукции. Например, в Бельгии функции прослеживаемости и идентификации входят в компетенцию Федерального агентства безопасности пищевой цепи (Federal Agency for the Safety of the Food Chain - FASFC), подчиненного Министру здравоохранения. Оно контролирует продукцию и сырье на всех стадиях цепи производства и реализации, включая сельскохозяйственное производство, обработку, хранение, транспортировку, торговлю, импорт и экспорт [7]. В Канаде координатором развития национальной системы отслеживания свиней от рождения до убоя является Канадский совет по свинине - Canadian Pork Council (CPC) [1].

Относительно стимулирования качества сельскохозяйственной продукции следует отметить развитие косвенных методов, то есть не связанных непосредственно с оплатой за продукцию. В частности, американский опыт показывает актуальность стимулирования качества продукции посредством проведения конкурсов. Так, National Mastitis Council - некоммерческая профессиональная организация, занимающаяся повышением качества молока и борьбой с маститом - ежегодно на протяжении более 20-ти лет с целью поощрения и признания производителей высококачественного молока проводит конкурс National Dairy Quality Awards. Спонсорами конкурса выступают такие компании, как Boehringer Ingelheim (фармацевтическая), GEA (производство техники), Milc Group (технологии), Hoard's Dairyman (журнал) и др.

Выбор победителя проходит по результатам двухуровневого онлайн-анкетирования, которое включает вопросы в области мониторинга здоровья животных, доения, протоколов для выявления и лечения клинических и субклинических маститов и др.

Следует отметить, что победители в качестве вознаграждения получают право бесплатного членства в National Mastitis Council в течение года [9].

Особенностью ряда стран является разработка программ стимулирования качества, которые содержат не только требования к производственному процессу 
и характеристикам продукции, но и к системе контроля, оплаты и т. д.

Так, например, в Канаде разработана программа Raw Milk Quality Program Policies, в соответствии с которой производители, не отвечающие минимальным критериям как к процессу производства, так и качеству молока, подпадают под санкции в виде штрафа или лишения лицензии на производство.

Область проверки включает: безопасность; поверхности, контактирующие с молоком; хранение и охлаждение молока; сооружения; уход за животными (в соответствии с Кодексом практики, Декларацией о здоровье крупного рогатого скота и ветеринарной медицине) и др. Каждый контролируемый пункт оценивается исходя из трех уровней соблюдения требований.

По результатам проверки предусмотрена градация фермеров на классы (по степени ухудшения результатов): класс A; условный класс A; не класс A; антисанитарные, не относящиеся к классу А.

Как показал анализ, в числе стимулов для соблюдения установленных требований среди приоритетных следует выделить:

- зависимость частоты проверки от присвоенного класса;

- платный характер проверок;

- штрафные санкции по результатам проверок с учетом присвоенного класса.

Так, например, фермеры, отнесенные к классу А, проверяются каждые два года, а не относящиеся к классу А (самый низкий уровень оценки), подлежат проверке каждые три - шесть месяцев. При этом все проверки, за исключением первой в течение двухлетнего периода, оплачиваются фермером.

Что касается штрафов, то они применяются за каждый месяц, когда фермер не соответствует классу А. Сумма штрафов зависит от степени и периода несоблюдения требований. При периодическом несоблюдении (3 месяца и более) фермер исключается из списка поставщиков [2, 10].

В целом изучение зарубежного опыта регулирования качества продукции аграрной отрасли посредством рассмотренных элементов указывает, что на современном этапе приоритетное значение принадлежит обеспечению производства продукции, отвечающей установленным требованиям, во взаимосвязи с экономическим аспектом данной проблемы, что выражается, прежде всего, в оптимизации систем контроля, прослеживаемости продукции, стимулирования устойчивости ее качества.

\section{Список использованных источников}

1. Canadian Pork Council [Electronic resource]. - Mode of access: https://www.cpc-ccp.com. - Date of access: 12.10.2019.

2. Dairy Farmers of Ontario [Electronic resource].-Mode of access: https://www.milk.org/. - Date of access: 03.09.2019.

3. European Commission website [Electronic resource] // European Commission. - Mode of access: https://ec.europa. eu/info/index_en. - Date of access: 15.09.2019.

4. Food Safety New [Electronic resource]. - Mode of access: https://www.foodsafetynews.com/?s=canada. Date of access: 03.09.2019.

5. Global food safety resource [Electronic resource]. Mode of access: https://globalfoodsafetyresource.com/brccertification/. - Date of access: 15.09.2019.

6. Healthy and safe food regulatory forum [Electronic resource] // WTO. - Mode of access: https://www.wto.org/ english/news_e/news14_e/sps_canada_july14_e.pdf. Date of access: 21.08.2019.

7. Identification and registration // Federal Agency for the Safety of the Food Chain [Electronic resource]. - Mode of access: https://www.fasfc.be/animals/identification-andregistration. - Date of access: 20.09.2019.

8. Justice Laws Website [Electronic resource] // Government of Canada. - Mode of access: https://laws-lois. justice.gc.ca/eng/regulations/SOR-2018-108/index.html/. Date of access: 03.09.2019.

9. National Dairy Quality Awards (NDQA) [Electronic resource] // NMC. - Mode of access: https://www.nmconline. org/ndqa/. - Date of access: 12.09.2019.

10. OMAFRA's Dairy Food Safety Program [Electronic resource] // Ministry of Agriculture, Food and Rural Affairs. Mode of access: http://www.omafra.gov.on.ca/english/ food/inspection/dairy/page-3-landing.htm\#32. - Date of access: 20.09.2019.

11. Regulation (EU) № 2019/1381 of the European Parliament and of the Council of 20 June 2019 on the transparency and sustainability of the EU risk assessment in the food chain [Electronic resource] // European Commission. Mode of access: https://eur-lex.europa.eu. - Date of access: 18.09.2019.

12. Regulation (EU) № 2017/625 of the European Parliament and of the Council of 15 March 2017 on official controls and other official activities performed to ensure the application of food and feed law, rules on animal health and welfare, plant health and plant protection products [Electronic resource] // European Commission. - Mode of access: https://eur-lex.europa.eu.-Date of access: 18.09.2019. 